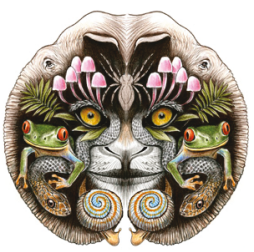

ISSN 0974-7907 (Online) ISSN 0974-7893 (Print)

OPEN ACCESS

\title{
FIRST HOST RECORD OF THE EULOPHID WASP TETRASTICHUS BILGIRICUS NARENDRAN (HYMENOPTERA: CHALCIDOIDEA) ALONG WITH THE FIRST DESCRIPTION OF A MALE FROM INDIA
}

Ankita Gupta ${ }^{1}$ \& Poornima Kannan ${ }^{2}$

${ }^{1}$ ICAR - National Bureau of Agriculturally Important Insects, Post Bag No. 2491, H.A. Farm Post, Bellary Road, Hebbal, Bengaluru, Karnataka 560024, India 2 210, Admiralty Manor, 13th0 Cross, 6th Main, Indiranagar, $2^{\text {nd }}$ stage, Bengaluru, Karnataka 560038, India 1'drankitagupta7@gmail.com (corresponding author), ${ }^{2}$ kannan.poornima@gmail.com

Abstract: Euthalia aconthea meridionalis Fruhstorfer (Lepidoptera: Nymphalidae) is documented as the first host record for the eulophid wasp Tetrastichus bilgiricus Narendran (Hymenoptera: Chalcidoidea) from Karnataka, India. The male of this species is recorded for the first time and described. Illustrations of both the female and male, and host details are given.

Keywords: Eulophid wasp, host record, Hymenoptera, Tetrastichinae, Tetrastichus bilgiricus.

Abbreviations used: $\mathrm{OOL}$ - Ocellocular distance; POL - Postocellar distance.
The genus Tetrastichus Haliday (Hymenoptera: Eulophidae: Tetrastichinae) is highly speciose containing 518 species worldwide (Noyes 2014). The species of this genus are often found associated with Lepidoptera, Diptera, Coleoptera and Hymenoptera. The main diagnostic characters of the genus Tetrastichus include a submarginal vein with one seta (rarely 2-4); a propodeum with a characteristic paraspiracular carina in the shape of an inverted ' $Y$ ' and a hind coxa with strong reticulations.

Tetrastichus bilgiricus Narendran (2007) was described from females collected in Bilgiri Rangaswamy Temple Wildlife Sanctuary (Karnataka). It is recorded here for the first time from the pupae of Euthalia aconthea
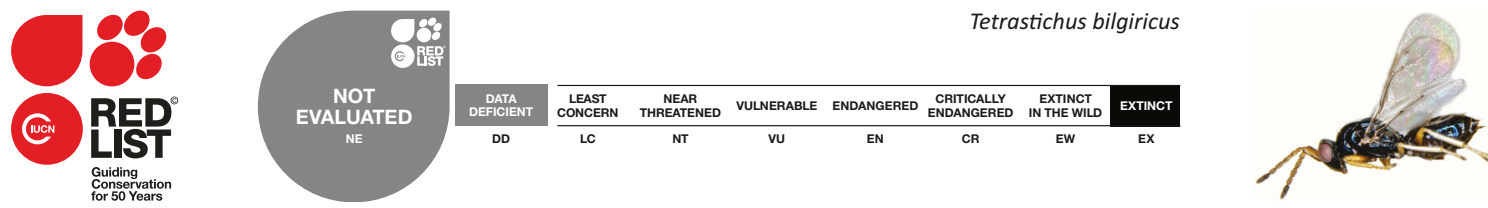

DOI: http://dx.doi.org/10.11609/JoTT.04051.6544-8 | ZooBank: urn:Isid:zoobank.org:pub:C86DDB8C-A3BD-44A4-BF3D-2BF5BBF1D5D2

Editor: John Noyes, Natural History Museum, London, UK.

Date of publication: 26 November 2014 (online \& print)

Manuscript details: Ms \# 04051 | Received 03 June 2014 | Final received 17 October 2014 | Finally accepted 04 November 2014

Citation: Gupta, A. \& P. Kannan (2014). First host record of the eulophid wasp Tetrastichus bilgiricus Narendran (Hymenoptera: Chalcidoidea) along with the first description of a male from India. Journal of Threatened Taxa 6(12): 6544-6548; http://dx.doi.org/10.11609/JoTT.04051.6544-8

Copyright: (C) Gupta \& Kannan 2014. Creative Commons Attribution 4.0 International License. JoTT allows unrestricted use of this article in any medium, reproduction and distribution by providing adequate credit to the authors and the source of publication.

Funding: Network Project on Insect Biosystematics funded by the Indian Council of Agricultural Research, New Delhi.

Competing Interest: The authors declare no competing interests.

Acknowledgements: AG thanks the Indian Council of Agricultural Research (ICAR) and Dr. Abraham Verghese (Director, NBAll) for necessary facilities. The taxonomic study is carried out under the Network Project on Insect Biosystematics funded by the ICAR. PK thanks A.S. Kannan and S. Karthikeyan for encouragement and guidance. We are grateful to reviewers for their efforts and time.

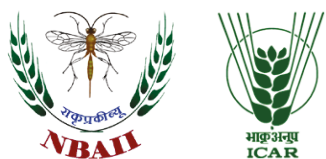


meridionalis Fruhstorfer (Lepidoptera: Nymphalidae). However, whether the present host association is a result of primary parasitism or secondary parasitism is still not clear. We provide here the first description of the male and a brief redescription of the female of $T$. bilgiricus along with illustrations and host details.

\section{Material AND Methods}

The wasps were collected from Bengaluru, Karanataka from parasitized pupae of $E$. aconthea meridionalis attached to a leaf of Mangifera indica L. (Image 10). Narendran (2007) was consulted for identification. A
LEICA M 205A stereozoom microscope with a LEICA DC 420 inbuilt camera using automontage software (version 3.8) was used for imaging. All measurements are given in millimeters. The voucher specimens are deposited in the National Bureau of Agriculturally Important Insects, Bengaluru (NBAII).

\section{Tetrastichus bilgiricus Narendran}

(Images 1-9, 11-19)

\section{Material examined}

NBAll/Eul/Tetra/bilg/25114, 25.i.2014, 30 females,
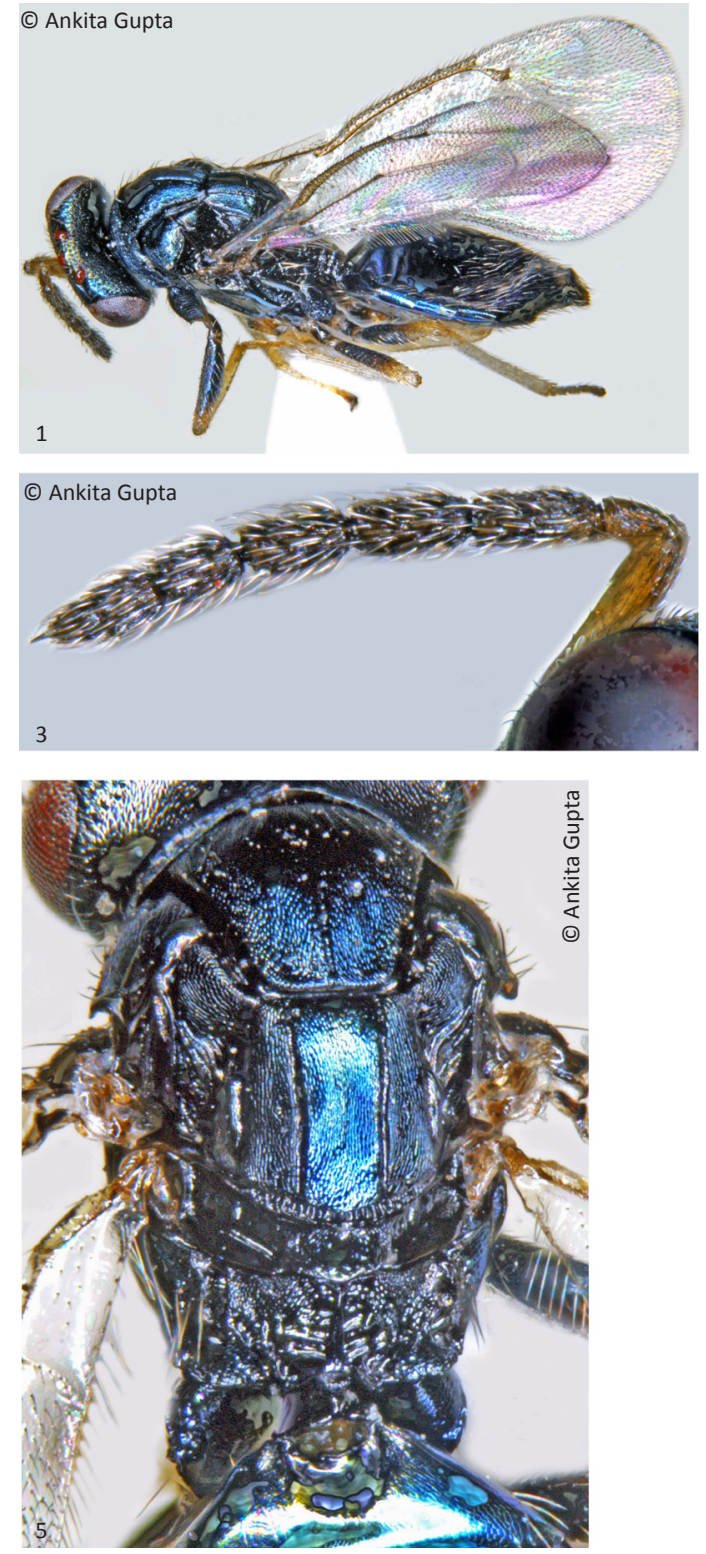

Images 1-6. Tetrastichus bilgiricus female

1 - Female, profile view; 2 - Head in frontal view; 3 - Antenna; 4 - Wings; 5 - Mesosoma; 6 - Propodeum with metasoma 

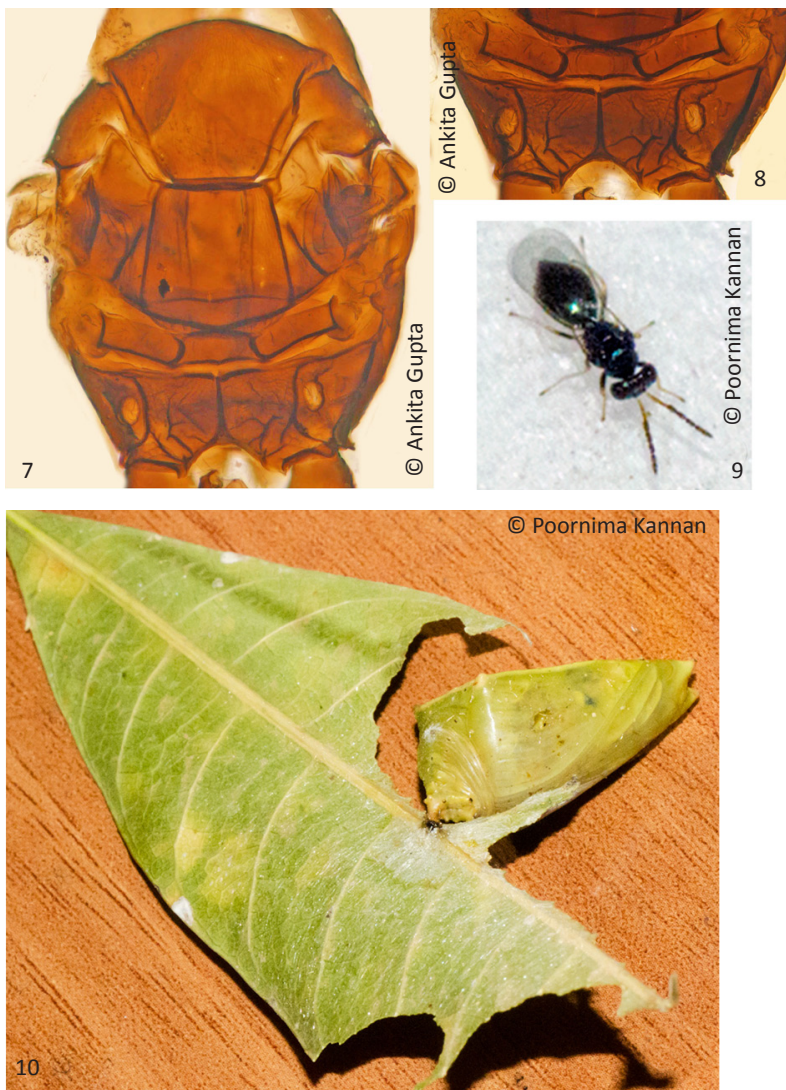

Images 7-10. Tetrastichus bilgiricus female

7 - Mesosoma (KOH treated); 8 - Propodeum; 9- Habitus;

10 - Host-parasitised pupa of Euthalia aconthea meridionalis.

10 males, Bangalore, Karnataka, India; ex. pupa of Euthalia aconthea meridionalis Fruhstorfer on Mangifera indica L.; coll. Poornima Kannan.

\section{Female}

Body length $2.48-2.68 \mathrm{~mm}$. Body black with metallic blue-green reflection (Image 1). Eyes brown. Ocelli red brown. Antenna dark brown with scape and pedicel paler (Image 3). Tegula dark brown. Wings hyaline, veins brown. Femora black with metallic shine, apices pale yellow; fore tibia and tarsi pale yellow, mid and hind tibiae and tarsi off white; pretarsi brown.

Head (Image 2): Head finely reticulate, $1.37 \times$ as wide as long in frontal view; POL $1.6 \times \mathrm{OOL}$; eyes sparsely setose, $1.90 \times$ as long as wide in frontal view, $1.74 \times$ as long as malar suture; malar suture straight. Antennal formula 11142 , scape reaching level of vertex. Measurementsscape: pedicel: clava (length) $=0.26: 0.11: 0.20$. Length: width funicular segments 1-4: F1 (0.16: 0.08); F2 (0.17: 0.08); F3 (0.16: 0.08); F4 (0.12: 0.07); clava (0.20: 0.07).

Mesosoma (Image 5): $1.15 \times$ as long as wide, $0.92 \times$ as long as metasoma, five adnotaular setae on each side

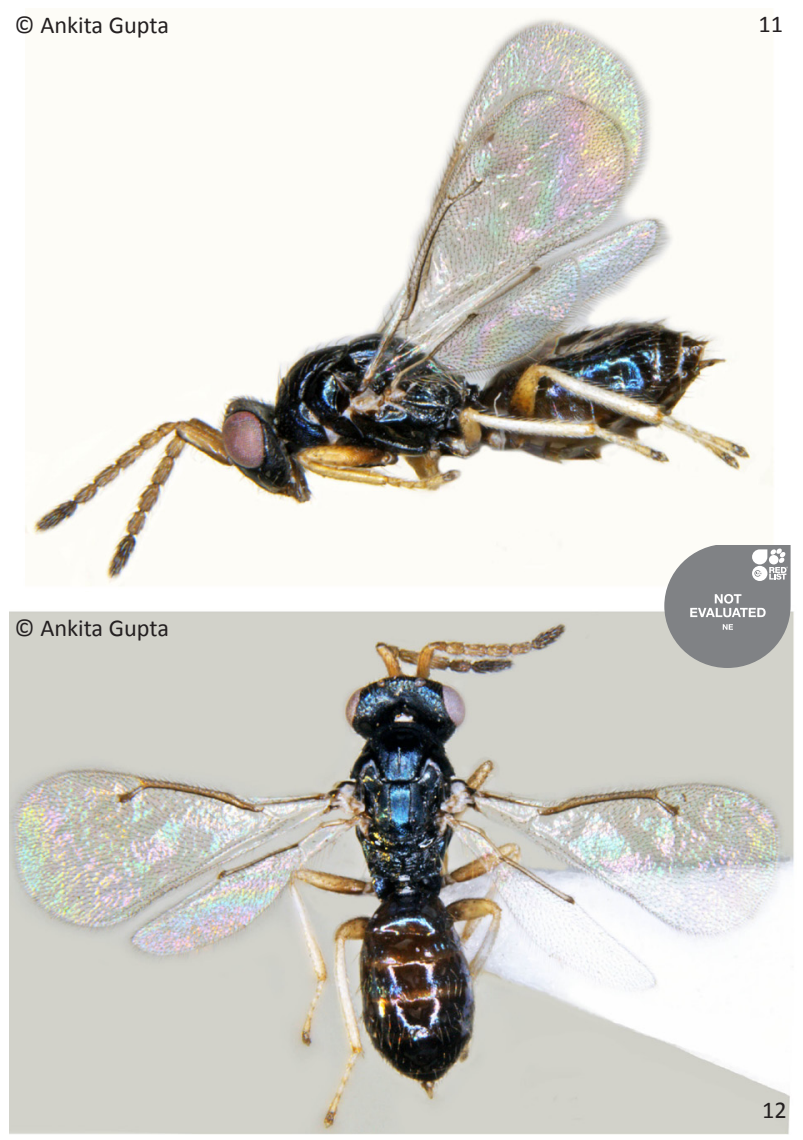

Images 11-12. Tetrastichus bilgiricus male 11 - profile view; 12 - dorsal view

of mesoscutum, medial line on mesoscutum indistinct anteriorly; scutellum $1.05 \times$ as wide as long, submedian grooves nearer to sublateral groove than to each other. Fore wing $2.12 \times$ as long as wide (Image 4); marginal vein $1.1 \times$ as long as costal cell, $3.71 \times$ as long as stigmal vein, speculum closed, line of setae extending from speculum above posterior edge of fore wing; submarginal vein with four setae; marginal fringe $0.27 \times$ as long as stigmal vein. Measurements- Mesosoma: metasoma (median length) $=1.11$ : 1.24 ; fore wing (length: width) $=2.18$ : 1.03; costal cell: marginal vein: stigmal vein $=0.55: 0.61$ : 0.17 .

Metasoma (Image 6): Sessile, 1.29× as long as wide.

\section{Male}

Body length 2.39-2.49 mm. Body in profile and in dorsal view (Images 11, 12). Body black with metallic blue-green reflection; clypeal region with symmetrical patch of brown colour on either side; mandibles brown with apical margin; dark margin. Antenna (scape, anellus and funicular segments) pale yellow except dark brown clava (Image 17). Femora pale yellow except margins of 

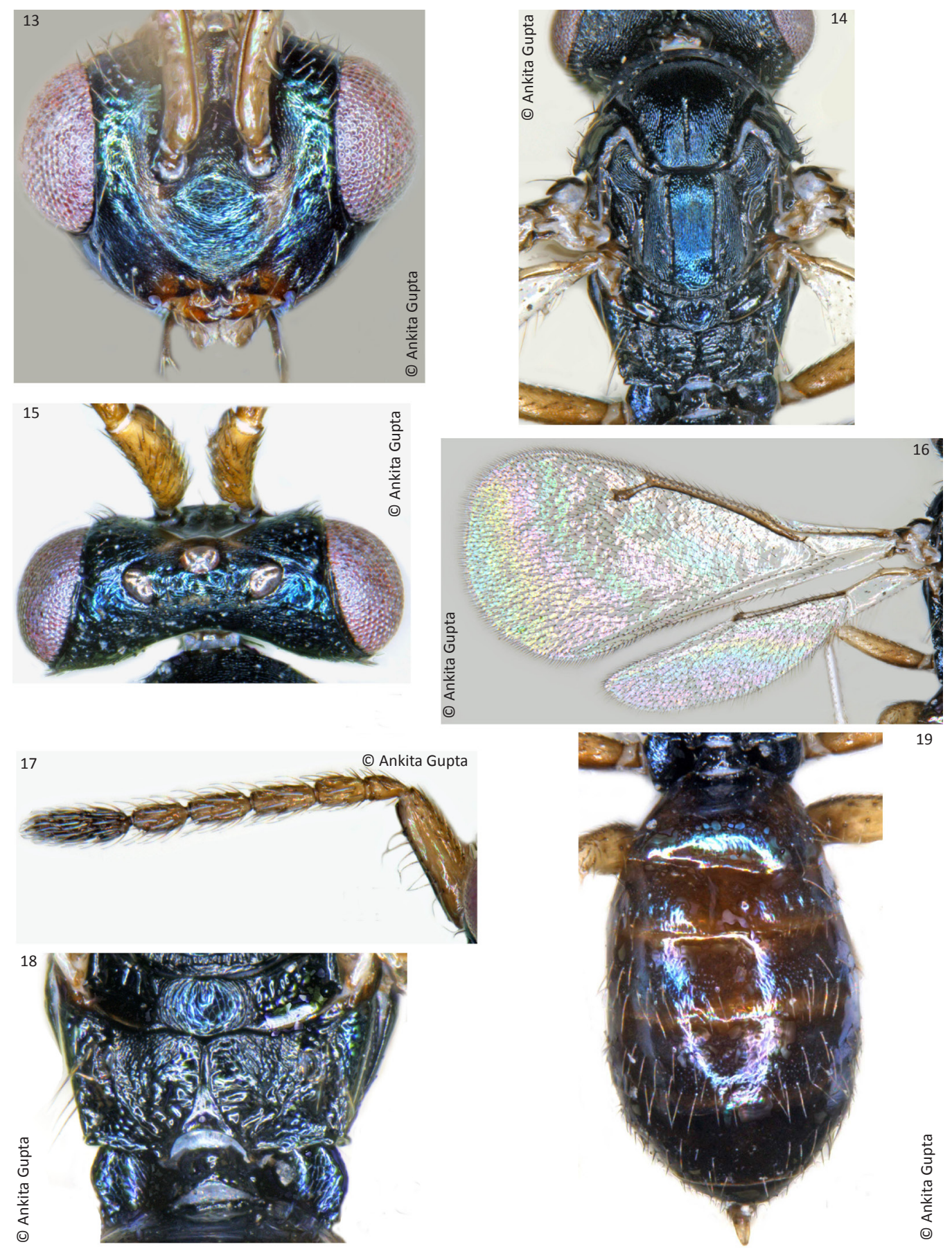

19

Images 13-19. Tetrastichus bilgiricus male

13 - Head in frontal view; 14 - Mesosoma; 15 - Vertex; 16 - Wings; 17 - Antenna; 18 - Propodeum; 19 - Metasoma

basal half and extreme base dark brown; fore tibia and tarsi pale yellow, mid and hind tibiae and tarsi white, pretarsi brown; tegula dark brown; coxae concolorous with mesosoma.

Head (Fig. 13): Head reticulate, $1.36 \times$ as wide as long in frontal view; POL 2.0× OOL; eyes sparsely setose, $2.08 \times$ as long as wide in frontal view, $1.76 \times$ as long as malar suture. Antennal formula 11142, scape reaching vertex; scape with a row of seven setae above ventral edge, dorsally with scattered setae (Fig. 17). Measurements (length: width)-scape (0.31: 0.09); pedicel (0.10: 0.05); anellus (0.01: 0.03); F1 (0.09: 0.06); F2 (0.13: 0.06); F3 (0.13: 0.06); F4 (0.11: 0.06) and clava (0.23: 0.07).

Mesosoma (Fig. 14): $1.17 \times$ as long as wide, five 
adnotaular setae on each side, medial line indistinct anteriorly; scutellum $1.04 \times$ as wide as long, submedian groove nearer to sublateral groove than to each other. Fore wing $2.04 \times$ as long as wide (Image 16); marginal vein $1.02 \times$ as long as costal cell, $3.2 \times$ as long as stigmal vein; speculum closed, with a line of setae extending from speculum above posterior edge of fore wing; submarginal vein with 3-4 setae; marginal fringe $0.33 x$ as long as stigmal vein. Mid tibial spur $0.97 \times$ as long as midmetatarsus. Measurements-Mesosoma: metasoma (median length) $=1.10: 0.91$; costal cell: marginal vein: stigmal vein $=0.47: 0.48: 0.15$.

Metasoma (Fig. 19): Sessile, dark brown with metallic reflection more pronounced in the posterior half, $1.21 \times$ as long as mesosoma and $1.88 \times$ as long as wide.

\section{Host}

The only parasitic wasp reported so far from Euthalia phemius Doubleday is Brachymeria lasus Walker (Noyes 2014). The present discovery is thus the first record of the parasitic wasp, T. bilgiricus, from Euthalia aconthea meridionalis.

\section{Discussion}

This species differs from other Oriental species in having the submarginal vein with four setae; antenna with one anellus; pedicel shorter than F1; costal cell a little shorter than marginal vein in female and subequal in male; mid lobe of the mesoscutum with incomplete median longitudinal groove; and metasoma shorter than mesosoma or almost subequal (Narendran 2007).

\section{REFERENCES}

Narendran, T.C. (2007). Indian chalcidoid parasitoids of the Tetrastichinae (Hymenoptera: Eulophidae). Records of the Zoological Survey of India, Occasional Paper No. 272: vi+1-385, plates I-IV.

Noyes, J.S. (2014). Universal Chalcidoidea Database. World Wide Web electronic publication.http://www.nhm.ac.uk/chalcidoids. (accessed, $3^{\text {rd }}$ September2014). 